\title{
High-yield purification of an organic solvent-tolerant lipase from Pseudomonas sp. strain S5
}

\begin{abstract}
An organic solvent-tolerant S5 lipase was purified by affinity chromatography and anion exchange chromatography. The molecular mass of the lipase was estimated to be $60 \mathrm{kDa}$ with 387 purification fold. The optimal temperature and $\mathrm{pH}$ were $45^{\circ} \mathrm{C}$ and 9.0, respectively. The purified lipase was stable at $45{ }^{\circ} \mathrm{C}$ and $\mathrm{pH}$ 6-9. It exhibited the highest stability in the presence of various organic solvents such as n-dodecane, 1-pentanol, and toluene. Ca2+ and $\mathrm{Mg} 2+$ stimulated lipase activity, whereas EDTA had no effect on its activity. The S5 lipase exhibited the highest activity in the presence of palm oil as a natural oil and triolein as a synthetic triglyceride. It showed random positional specificity on the thin-layer chromatography.
\end{abstract}

Keyword: Organic solvent-tolerant lipase, Pseudomonas sp. strain S5, Purification, Characterization 